\title{
La instalación como herramienta metodológica en Educación Infantil: un estudio de caso
}

\section{Art Installations as a Methodological Tool in Preschool Education: A Case Study}

Ainhoa Gómez-Pintado (*) https://orcid.org/0000-0003-4124-9665

Ana Zuazagoitia Rey-Baltar (*) https://orcid.org/0000-0002-1256-1695

Maria Teresa Vizcarra Morales (*) https://orcid.org/0000-0002-9369-9740

(*) Universidad del País Vasco

(Recibido: 25 de octubre de 2018; Aceptado para su publicación: 18 de febrero de 2019)

Cómo citar: Gómez-Pintado, A., Zuazagoitia, A. y Vizcarra, M. T. (2020). La instalación como herramienta metodológica en educación infantil: un estudio de caso. Revista Electrónica de Investigación Educativa, 22, e23, 1-13.

https://doi.org/10.24320/redie.2020.22.e23.2678

\section{Resumen}

Se presenta un estudio de caso sobre instalaciones artístico-educativas como herramienta metodológica para el ciclo 0-31', realizado en dos escuelas municipales de educación infantil de Vitoria-Gasteiz (España), analizando sus experiencias y comparándolas con las propuestas de Javier Abad, experto en el tema. Se busca comprender cuáles son sus características y beneficios para determinar las claves que faciliten posteriores implementaciones. La información obtenida de registros audiovisuales, notas de campo y entrevistas fue categorizada y analizada mediante el programa digital NVivo 11. Los resultados apuntan al carácter beneficioso de estas instalaciones en el aprendizaje y desarrollo autónomo de los niños, y en la evolución personal del profesorado, develando la complejidad del papel de los profesores responsables de diseñar, documentar y acompañar este proceso. Estas experiencias, cuando son compartidas por la mirada adulta y la de la infancia, develan una práctica en la que el proceso de creación marca el aprendizaje de los participantes.

Palabras clave: Innovación educacional, formación de profesores, educación de la primera infancia.

\section{Abstract}

This article presents a case study on school art installations as a methodological tool for the 0 to 3 -year-old cycle. The study was conducted in two municipal nursery schools in Vitoria-Gasteiz (Spain) and consisted in examining their experiences and comparing them with the proposals of Javier Abad, an expert on the subject. The aim is to understand the characteristics and benefits of these experiences to determine the key elements that would facilitate future implementations. The information obtained from the audiovisual records, field notes, and interviews was categorized and analyzed using the digital software NVivo 11. The results suggest these installations have a beneficial effect on children's learning and autonomous development and on teachers' personal growth, while revealing the complex role played by teachers in charge of designing, documenting, and supporting this process. When shared by the perspectives of both the adults and the children, these experiences unveil a practice in which participants' learning is shaped by the creation process.

\footnotetext{
${ }^{1}$ El 0-3 responde al primer ciclo de educación infantil en España; el 3-6 sería el segundo ciclo. Habitualmente se hace referencia a ellos como 0-3 y 3-6.
} 
Keywords: Educational innovation, teacher training, preschool education.

\section{Introducción}

El arte, parte fundamental del desarrollo integral de los niños, potencia la creatividad, la sensibilidad, el sentido estético (...) (Panadés y Balada, 2007) y supone para la infancia una de las primeras manifestaciones de expresión y comunicación personal. Una vía para entender el mundo que les rodea, aumentar su autoconocimiento y resolver nuevos problemas a través de múltiples experiencias (Aguirre, 2015).

Tradicionalmente la educación artística incidía en desarrollar capacidades técnicas a través de la reproducción imitativa y el aprendizaje memorístico, dejando de lado aspectos creativos y emocionales (Andueza et al., 2016). La evolución constructivista de la educación (Aguirre, 2015) ha reivindicado la importancia del aprendizaje por descubrimiento convirtiendo a los niños en protagonistas de su propio conocimiento y al arte contemporáneo en base fundamental para el planteamiento de nuevas experiencias educativas (Marín, 2014). Dichas experiencias permiten desarrollar capacidades de reflexión, emoción, imaginación, percepción e interpretación acercando al alumnado a su mundo social y cultural, a través de propuestas que invitan a múltiples interpretaciones y juegos simbólicos (Andueza et al., 2016).

Entre las formas a través de las cuales el arte está presente en la escuela (cultura visual, música, teatro, danza, etc.), una de las propuestas actuales más interesantes es la utilización de las instalaciones educativas, que tienen en las artísticas un claro referente.

Aunque la naturaleza ecléctica de la instalación artística implica permanentes relecturas e interpretaciones que imposibilitan definiciones unívocas, se puede intentar delimitar su carácter plural a través de ciertas características, como la ubicación de elementos en coordenadas espacio-temporales (Sánchez, 2008) y, principalmente, la presencia literal de espectadores (Bishop, 2008). Esta presencia marca la diferencia, ya desde su nacimiento en los años sesenta, respecto a los medios tradicionales (escultura, pintura, fotografía...) en los cuales la obra realizada por artistas-creadores se interpreta por espectadoresreceptores requiriendo únicamente de la contemplación visual. Por el contrario, las instalaciones "en lugar de representar texturas, espacios, luz, etc., (...) presentan estos elementos de modo directo para que los experimentemos". (Bishop, 2008, p. 46).

Mediante la instalación, tanto artística como educativa, y sus "estrategias de presentación de los objetos y su puesta en escena" (Abad, 2011, p. 8), se activa la atención del participante a través de la sorpresa, la evocación, la seducción estética, etc.

El público da sentido a la obra al transformarla e interpretarla, permitiendo la manifestación de aspectos perceptivos y vivenciales y la experimentación artística consciente, libre (Díaz-Obregón, 2003) y personal, ya que cada elemento puede ser utilizado de forma variable, en distintos tiempos y momentos según las propias necesidades (Larrañaga, 2016). El carácter efímero de la instalación que se modifica, se destruye o se desmonta, insiste aún más en esta experiencia en primera persona (Bishop, 2008).

Lo fundamental no es conseguir un producto final de carácter estético o artístico, sino el proceso en sí. Es por ello que no se trata de "hacer arte" sino de "experimentar arte" (Díaz-Obregón, 2012), sin la presión de saber o no saber hacer y con la libertad de experimentar vivencias en las que se ponen en juego las capacidades creativas, sociales e intelectuales. Además, permiten el desarrollo y disfrute a través de procesos no sólo visuales debidos a la estimulación estética y sensorial que los espacios y materiales ofrecen, sino también auditivos y kinestésicos por la verbalización que acompaña a sus acciones y que da diversos sentidos a lo realizado, y porque a través del movimiento corporal experimentan y expresan lo sentido (Traveset et al., 2017).

El resultado son múltiples propuestas de aprendizajes fundamentales -creatividad, búsqueda de soluciones, respeto y sensibilidad hacia las creaciones, etc.- tanto en el ámbito del arte como en el de la educación, tanto en el ámbito de la cultura visual como en las demás áreas (Duncum, 2001).

La instalación en Educación Infantil facilita la transformación de la comunidad educativa en un foro de actuación y ámbito de creación para pensar, sentir y actuar (Abad, 2012) posibilitando, además, la presencia del arte como elemento no estandarizado en la vida cotidiana del alumnado (Marín, 2014). 


\subsection{Espacio, objetos y estética en las instalaciones en educación Infantil}

A la hora de realizar una instalación en la escuela hay que tener en cuenta los espacios, los objetos y la estética. Las instalaciones deben plantear el espacio como totalidad, y no fragmentado o a modo de rincones, que permita "los movimientos inesperados del pensamiento y la libertad de circular libremente" (Callejón y Yanes, 2012, p. 146).

Estos espacios, así como los objetos y materiales que los configuran, deben responder a una serie de objetivos comunes: estar abiertos a la interpretación, modificación y apropiación para permitir a los infantes construir narraciones y conocimientos propios, basados en su experiencia cotidiana (Dewey, 2010); ofrecer recorridos abiertos y diversos capaces de atender a los distintos ritmos y posibilitar diferentes vivencias e interacciones tanto individuales como cooperativas (Ruiz y Rebollo, 2015).

No se trata de decorar un espacio ni de imitar las instalaciones artísticas, sino de ofrecer un lugar y un tiempo evocador y estimulante, abierto a recibir nuevos valores y significados (Hoyuelos et al., 2015), que faciliten la creación del imaginario de la infancia (Abad y Ruiz de Velasco, 2014).

Para facilitar estas apropiaciones y simbolizaciones personales es aconsejable utilizar materiales y objetos relacionales, definidos por la artista Lygia Clark (como se citó en Abad, 2011) como cajas, hilos, telas, etc., de diferentes colores, texturas y percepciones (Abad y Ruiz de Velasco, 2014). Estos objetos permiten otorgar y comunicar distintos significados, dependiendo de la persona e incluso del momento, aumentando las posibilidades de expresión en comparación con aquellos objetos y materiales que al ser réplicas de la realidad suelen tener significados concretos.

Los materiales y objetos atractivos y polivalentes, así como su disposición, ordenada y accesible para el alumnado, potenciarán nuevas ordenaciones y múltiples transformaciones y construcciones, propiciando la destrucción del orden que la persona adulta ha creado para permitir el desorden como apropiación e interpretación del espacio, para "hacerlo propio" (Abad, 2008, p. 173).

Por último, el equipo docente deberá definir en su planteamiento la estética, dada su importancia en el contexto educativo como refuerzo de las situaciones de aprendizaje al proporcionar contextos perceptivamente gratificantes y entendiendo lo estético como el eje fundamental de un ambiente de aprendizaje atractivo y motivador, un espacio potenciador de significaciones, preparado para la experimentación especialmente sensorial, afectiva y relacional, y estimulador de la creatividad (Malaguzzi, 2014).

\subsection{Proceso y uso de las instalaciones artístico-educativas}

Las personas adultas (profesorado, artistas invitados, tallerista, etc.) serán quienes diseñen la instalación encargándose de la escenografía, es decir, deberán plantear los escenarios y objetos de la instalación basándose en la observación de las necesidades del alumnado.

Dado que los niños van a enfrentarse a un espacio nuevo y desconocido, que puede generarles situaciones de ansiedad o inseguridad, es aconsejable realizar una presentación del espacio, materiales u objetos que se van a encontrar. Puede ser sencillamente una breve descripción del profesorado, acompañada por la posibilidad de tocar los materiales empleados. Esta presentación puede complementarse con la realización de un dibujo que permita al alumnado adelantar en el pensamiento las hipótesis sobre las acciones que realizarán, acrecentando el deseo por el juego (Abad, 2008). También, al final de la acción se puede realizar otro dibujo que plasme la experiencia vivida. En este caso, Abad (2012) apunta que:

A diferencia de los dibujos previos, más descriptivos y analíticos, estos últimos están más interesados en representar la figura humana de manera grupal y también son muy narrativos en la interpretación de la acción lúdica mediante grafismos y líneas de gran dinamismo (p. 7).

Una vez presentada la instalación, los infantes pueden entrar en la misma. En ella se darán distintas formas de convivencia y las acciones serán libres, aunque siempre existirán límites y normas básicas de comportamiento, garantes de la seguridad y evolución del alumnado. 
El proceso habitual de intervención libre suele venir precedido de una destrucción-simbólica, seguida por la construcción o reconstrucción mediante la transformación de los materiales y el espacio; proceso que se repite de manera cíclica hasta acabar el juego, bien de motu proprio, bien por cuestiones temporales (Abad, 2008). Al igual que ocurre con otras propuestas de psicomotricidad, los niños, a través del placer de la destrucción, comprueban su capacidad de dominio, afirman su identidad y se proyectan "en el espacio por medio de las construcciones simbólicas" (Aucouturier, 2004, p. 177). Este proceso es fundamental ya que, si bien el orden (presente a través de las rutinas) es un elemento primordial en el ciclo de infantil al proporcionar seguridad y ayuda en la interiorización de las organizaciones espacio-temporales; el caos, al ser un momento para la creación e interpretación propias, es un complemento necesario que refuerza, y responde a la diversidad de las personas. (Harf, 2008).

La tendencia en el uso de los objetos pasa también de una primera fase en la que los niños utilizan los objetos siguiendo parámetros convencionales a una segunda en la que su uso será simbólico; asimismo, pasarán del juego individual al colectivo (Abad, 2008).

Mientras el alumnado interacciona entre sí y con la propia instalación, la función del profesorado será acompañar y documentar. Es fundamental registrar los sucesos del aula mediante videos y fotografías junto con notas de campo etnográficas (Callejón y Yanes, 2012), ya que una práctica educativa reflexiva conlleva el análisis en tres tiempos -antes, durante y después- y la comprensión, o simplemente la percepción, durante la propia práctica resulta complicada al ser muchos los factores que entran en juego y los acontecimientos que se suceden de manera conjunta.

La documentación de la vivencia permite valorar posteriormente la instalación planteada al detectar el placer o el desagrado, observar las modificaciones y variaciones realizadas en las funciones y formas de objetos y materiales, o el estancamiento al repetir acciones, posturas o juegos (Abad, 2008). La observación proporcionará un mayor conocimiento de sus necesidades y caracteres al detectar los roles que se asumen, las relaciones de colaboración o imposición, etc., ayudando a reflexionar al docente sobre la práctica realizada y, en algunos casos, a sistematizar ciertos aspectos de la propuesta.

\section{Método}

El presente estudio de caso parte de un paradigma interpretativo con el objetivo de comprender una realidad educativa; en concreto, qué ocurre con las instalaciones artístico-educativas que han puesto en práctica dos escuelas de 0-3 años de la Red de Escuelas Municipales de Educación Infantil (EIMU) de VitoriaGasteiz (España) en colaboración con la Escuela de Artes y Oficios de la ciudad. La perspectiva cualitativa ayudará a entender los beneficios que estos espacios aportan a los niños, así como al profesorado y, por ende, al centro y a las familias. Con el análisis de estas experiencias se busca develar ante el profesorado las claves en el diseño y uso de las instalaciones, así como sus características, para que puedan implementarlas en el aula y conseguir los resultados de aprendizaje deseados.

Las Jornadas de Arte y Pequeña Infancia, celebradas en la Facultad de Educación y Deporte de VitoriaGasteiz, tuvieron como eje temático el uso de las instalaciones artístico-educativas en Educación Infantil. Las Jornadas permitieron entrar en contacto con el planteamiento metodológico de los espacios de simbolización mediante instalaciones del profesor Javier Abad, de la Universidad de Alcalá de Henares (Madrid), y con las EImu; lo que posibilitó, posteriormente, observar el trabajo que estas escuelas realizan en colaboración con la Escuela de Artes y Oficios.

El escenario fueron las Escuelas de Educación Infantil en las que se llevó a cabo la experiencia, a través de las observaciones de lo que ocurría con las instalaciones y las entrevistas a sus directoras y maestras utilizando un guion elaborado ad hoc.

La recogida de datos se realizó a través de diferentes herramientas, entre las que destacan las notas de campo tomadas por las investigadoras (al menos tres personas observaban la acción y contrastaban sus notas), registros de video y audio con sus correspondientes transcripciones, y las transcripciones de las entrevistas. Para identificar la fuente (manteniendo su anonimato) y el instrumento de recogida de la información, se utilizaron diferentes códigos:

\section{- Transcripción de la intervención de Javier Abad (CA).}


- Transcripción de la entrevista a representantes de la Escuela de Artes y Oficios (EEA).

- Transcripción de la entrevista a las profesionales de la Escuela Municipal Infantil (EP1, EP2... EP4).

- Notas de campo de las investigadoras realizadas durante las intervenciones de las profesionales de la Escuela Municipal Infantil (NC 11, 12 .. 17).

Para el estudio se optó por un análisis de contenido, donde la información obtenida se organizó y estructuró a través de un sistema categorial jerarquizado. El proceso seguido para el análisis de la información ha sido inductivo, dinámico y sistemático. Ha requerido conocer, comparar, escoger e interpretar el significado de las voces y las notas de campo recogidas. En el sistema categorial se definieron las categorías y subcategorías (ver tabla I), que fueron introducidas en el programa digital NVivo 11 para analizar la información cualitativa mediante nodos ramificados.

Tabla I. Sistema categorial sobre las instalaciones en Educación Infantil

\begin{tabular}{|c|c|}
\hline Categoría & Subcategoría \\
\hline \multirow{5}{*}{ 1. Instalaciones artístico-educativas en la escuela } & Objetivos \\
\hline & Características \\
\hline & Estética \\
\hline & Tipos de instalaciones \\
\hline & Aprendizajes \\
\hline \multirow[b]{2}{*}{ 2. Comportamiento de niños y niñas } & Acciones de niños en las instalaciones \\
\hline & $\begin{array}{l}\text { Influencia de las estética materiales objetos } \\
\text { en las reacciones }\end{array}$ \\
\hline \multirow{3}{*}{$\begin{array}{l}\text { 3. papel del profesorado en el proceso } \\
\text { de trabajo }\end{array}$} & Presentacion de las instalaciones a los niños \\
\hline & Proceso durante la acción \\
\hline & Documentación de la experiencia \\
\hline \multirow{2}{*}{$\begin{array}{l}\text { 4. Tras la experiencia: cambios producidos tras la } \\
\text { realización de las instalaciones en el centro }\end{array}$} & Profesionales \\
\hline & Respecto a las familias \\
\hline
\end{tabular}

Una vez analizada y contrastada la información se obtuvieron los sumarios de cada una de las categorías, lo que permitió la construcción del correspondiente informe interpretativo. La triangulación de los datos es intersubjetiva, fue aportada por diferentes personas y fuentes de información, lo que dio una visión más objetiva a lo estudiado, pues la realidad fue construida reflejando las diferentes miradas que se dieron sobre un mismo hecho.

Por último, se organizó la documentación trabajada buscando la coherencia argumental, narrativa y explicativa en la redacción final.

\section{Resultados}

\subsection{Objetivos y características de las instalaciones en la escuela}

Las educadoras participantes destacan que a través del uso de las instalaciones en la escuela se pretende el desarrollo de la creatividad en los niños de una manera integrada y no desglosada en conocimientos y experiencias compartimentados, de forma que el aprendizaje tenga carácter global y motivador, que genere una inquietud y potencie el deseo de seguir aprendiendo:

Por ejemplo, se busca trabajar la creatividad... es una pena hacer las cosas con fichas, se puede trabajar todo de otra forma. En estas edades (0-2) no se pueden extrapolar o dividir las materias... todo se aprende "junto" y en este sentido estos espacios aúnan diferentes conocimientos, experiencias. (NC4).

Parte fundamental de esta motivación es la estética, alcanzando un equilibrio entre una estética cuidada y las necesidades de desarrollo del alumnado. Se trataba de crear: 
Un lugar atractivo, bello, emocionante. También para nosotros mismos. Hacer algo que nos gustara. (EEA).

Es recomendable dar el paso de la estética a la ética, para que, en lugar de ser bonito para los ojos sea adecuado para el juego. Tenemos que ser artistas de la educación y traer el placer a la educación. Nos tenemos que sorprender, nosotros y los niños, con aquello que están haciendo. (CA).

Se buscan estéticas alejadas de los estereotipos, que amplíen los referentes visuales del alumnado y salir de la rutina:

La estética influye mucho en los niños (por ejemplo, en nuestro caso nadie quería estar en el aula roja), las estéticas habituales que ven en casa son las estereotipadas e infantilistas (por ejemplo, los dibujos animados). Estas estéticas suponen darles más opciones, más perspectivas (EP4).

Tanto los materiales utilizados como su disposición en el espacio buscan, además del desarrollo estético, ampliar el abanico de posibilidades expresivas. Ello no significa que los materiales en sí tengan que ser especiales, sino que -por su selección y planteamiento- permitan ser utilizados y disfrutados de manera distinta a la habitual:

Usamos materiales que son habituales, pero que al mismo tiempo pueden dar resultados distintos, materiales no "formales" ni cerrados. (EP2).

Teniendo siempre presente que se deben ofrecer oportunidades abiertas a todo el alumnado y que se trata de proporcionar juego, no juguetes:

Permitir recorridos... Aquí hay juego de transformación, tiene que haber objetos para todos. No hace falta darle el juguete, hay que darle juego. (CA).

Las entrevistas con profesionales aportan que en el aprendizaje de los niños es imprescindible no perder de vista cuáles son los elementos que les ayudan realmente a desarrollar la creatividad y trabajar la parte emocional ampliando sus miradas y referencias visuales:

Es importante que tengan otras perspectivas, visiones, que no sean estereotipadas. Creatividad, el dejarles hacer, vivir, trabajar la parte emocional. Nos han limitado... te ponen límites... esa libertad para crear, sensaciones, emociones. (EP1).

Jugando con el espacio y los materiales, los niños podrán expresarse, desarrollarse, incidiendo en la inteligencia emocional:

Son espacios para ser, estar, emocionarte. Expresar, que se rían, no cortarles. Una herramienta fundamental es la emoción. La inteligencia emocional se debe trabajar. Cada niño desarrolla sus capacidades e interrelaciona con otros. (EP2).

Y también se trabaja la identidad a través de la imaginación, la magia, la sorpresa:

Están jugando "al como si", la magia, la sorpresa; pizarra que se abre y cierra; soy, no soy... Es un proceso intelectual de saber quién soy o no. La escuela infantil tiene una función que es saber quién soy. La identidad. También los adultos somos seres en tránsito. (CA).

Las entrevistas muestran que el reto era transformar el espacio cotidiano en un nuevo lugar, estimulante e impactante tanto para el profesorado como para el alumnado. En una primera instalación en las EIMU se optó por crear y colocar en un pasillo grandes flores de papel de seda, blancas y rojas, dispuestas en el suelo o colgando del techo. Este pasillo daba acceso, a través de un arco formado por cajas blancas, a un aula en la que estaban distribuidas varias cajas de cartón pintadas en colores vivos que contenían elementos propios del juego heurístico -pinzas para la ropa, serpentinas, pequeños conos, etc.- siguiendo el planteamiento mencionado de dar juego a través de objetos abiertos:

Les propusimos una actividad heurística: transformar el espacio cotidiano en un lugar impactante y que estimule a los niños y a las propias educadoras. El espacio a descubrir estaba aislado. Había 
que atravesar un pasillo blanco con nenúfares de papel por el camino para acceder a él. Creamos nenúfares de color blanco y alguno rojo. El color invitaba a recorrer el camino, aunque no sabíamos si ban a entrar o no. Al final del pasillo hay un montaje hecho con cajas, en ellas los niños pueden entrar, salir, buscar... se busca la curiosidad, la complicidad... (EEA).

Esta instalación se complementó con otra de naturaleza más plástica y centrada en la pintura realizada al día siguiente. El profesorado recuperó las cajas de cartón de la sesión anterior disponiéndolas de manera ordenada formando un círculo; intercalados entre las cajas se presentaron recipientes con temperas de colores; en el centro, rodillos y brochas también dispuestos formando un círculo. Todo ello en un espacio totalmente forrado de papel blanco que además de buscar una estética atractiva que invitase a entrar y experimentar, daba pie al alumnado a actuar no sólo sobre las cajas sino también sobre el suelo y las paredes:

En la experiencia del segundo día, cada uno elige su momento para transformarlo todo. Se utilizan las cajas del día anterior pintadas, todos los elementos están presentados de una manera estética y bella, ordenados. Su estética invita a entrar (NC2).

La intención del papel blanco no era que no se ensuciase lo que había debajo, sino que pudiesen pintar tranquilamente (EEA).

Esta reutilización de los elementos de una instalación en otra cambiando su orden, posibilita el planteamiento de diferentes espacios que a su vez propician nuevos juegos y experimentaciones:

Cada instalación se puede reutilizar. Se pueden colocar los objetos de otras maneras o plantear diferentes tipos de juegos: primero el juego sensorio-motor, luego el juego simbólico... (CA).

Otra instalación, compuesta por un gran círculo de arcilla, se realizó en el jardín exterior de una de las escuelas:

Pensamos en sacarles del aula para romper esquemas. Nos atraía la idea del contraste entre la hierba verde y la arcilla roja. Pusimos un plástico sobre la hierba e hicimos una especie de galleta María enorme cuadrada. El profesor de cerámica la dejó totalmente plana con un rodillo. Al final redondeamos la galleta y pusimos guijarros blancos alrededor. Para invitar a entrar pusimos en el centro un círculo blanco y unas garzas de papel, una roja y otra verde de tipo japonés. Pensamos que a los niños les iban a resultar atractivas e iban a querer cogerlas. También colocamos unos trozos enrollados de barro (como si fuesen tornillos) en algunos puntos alrededor del círculo (EEA).

\subsection{Los niños ante las instalaciones}

El comportamiento de los niños ante estas propuestas son muy distintos dependiendo de la persona y del grupo. En general la primera reacción suele ser de sorpresa, junto con la duda de si pueden tocar lo que se les ofrece. Una vez alguien comienza el juego los demás se animan:

Primero miran y se sorprenden, buscan la mirada de la profesora para saber a ver si pueden, no pueden, o hasta dónde pueden actuar. Al ver que uno normalmente se lanza y va el primero, los demás le siguen. (EP4).

Cuando comprueban que la persona adulta permite el juego comienzan la acción, deconstruyendo aquello que se presenta ante ellos:

En el momento en que están seguros se meten en su mundo, en su juego, empiezan a desordenar creando el caos. Después comienzan a realizar nuevas construcciones y el ciclo se repite. (EP3).

De repente descubren otro plano, el plano vertical, las paredes también se pueden pintar. De repente un niño empieza a pintar la pared, cuando ve que no le pasa nada especial, que nadie le dice nada, sigue pintando la pared. (EEA).

Esta primera acción de los niños, la destrucción simbólica, se repite también en las experiencias llevadas a 
cabo por Abad:

La destrucción simbólica, el tirar las cosas... no es deshacer sino deconstruir. Después viene el movimiento, dándole al cuerpo toda la libertad hasta que el cuerpo se muestre colmado de movimientos. (CA).

Y la acción de deconstruir se incrementa cuanto mayor sea el orden inicial de los elementos de la instalación:

Cuanto más ordenado está, más nerviosos pone a los niños. Ejercen una acción de empoderamiento, te desestructuro y crezco. (CA).

No siempre la instalación y sus objetos tienen el éxito o el uso que se presuponía. Por un lado, la estética de la instalación es fundamental en relación con su capacidad para producir juego simbólico y sensoriomotriz. Si el aspecto de la instalación recuerda a algo sucio puede no resultar agradable o atractivo. Así ocurre con una de las instalaciones compuesta por un gran círculo de arcilla situado sobre la hierba del patio que recuerda a un "charco" o incluso a "caca":

Cuando llegaron al círculo de arcilla hubo un momento de expectación en el que no entraron ni decían nada. De repente una niña dijo "charco" y otra "caca". Esto es como decir "prohibido", les condiciona. (EEA).

Por otro lado, los elementos colocados en la instalación con una intención concreta pueden ser utilizados en un modo totalmente diverso e incluso peligroso; o aquellos que se pensaba que podían ser atractivos son ignorados:

Las piedras se convirtieron en objetos volantes. Se dieron cuenta del peligro que podían entrañar. Pasaron olímpicamente de las garzas, parecía que les estorbaban. Eran unas garzas atractivas, de papel charol en colores fuertes, pues ¡ni caso! No lo entendíamos, pero es así. (EEA).

Al mismo tiempo, elementos en los que no se había pensado y que fueron aportados por las educadoras, resultaron ser herramientas valiosas para el juego:

Las educadoras aportaron conchas, palitos. Con los palitos pueden perforar, con los dedos no tienen fuerza. Niños y niñas entran a saco. (EEA).

Pero, aunque el espacio sea atractivo y participen, hay algunos que no desean entrar en el juego, y hay que respetarlo:

Se respeta que no quieran ir a jugar. No tiene manual de instrucciones. (CA).

Por el contrario, otros encuentran la instalación tan atractiva que no quieren salir del espacio. Por ello, los tiempos de uso de la instalación dependen de cada persona, ya que estas acciones posibilitan que cada niño esté en el espacio y en la acción el tiempo que desee:

La mayoría de los niños cuando llevaban 40 minutos en ese espacio se fueron con naturalidad, recogieron las cosas, se quitaron la bata y se limpiaron las manos... pero 3 niños se quedaron hasta el final, más tiempo, no querían irse pues estaban totalmente dentro de la acción. (EEA).

Obviamente no siempre se puede dejar que el alumnado esté todo el tiempo que desee, por lo que es importante adelantarles el término de la acción avisando el final de la misma cinco minutos antes. En el caso de Abad, se concluye con la realización de un dibujo final en blanco y negro que ayude a interiorizar lo vivido:

Para terminar, se hace un dibujo, con líneas, en blanco y negro (la historia puede perderse en el color). En muchas ocasiones los dibujos en blanco y negro tienen más significados, ya que exige una mayor implicación. El dibujo, además, es válido para interiorizar lo realizado. (CA).

Asimismo, puede ser recomendable que pasado un tiempo se visualicen en grupo las imágenes tomadas 
con los niños protagonistas de la acción:

Como despedida ¿cómo es estar dentro del espacio como actores y después como espectadores activos? Visualizando las imágenes con ellos después. (CA).

\subsection{El papel del profesorado}

El papel del profesorado en las instalaciones es múltiple cómo diseñadores de la instalación, acompañantes y documentalistas:

La función del profesorado es: documentar la acción, el papel de escenógrafo y el de mediador entre los artistas y los niños. (EP2).

Estos papeles se distribuyen en tres tiempos. En un primer tiempo se presentan los materiales en el aula, propiciando la curiosidad y dando seguridad:

Primero presentamos los materiales en el aula, pero sin develar la sorpresa. Les preguntamos cosas como: "¿Qué sorpresa hay hoy?" de manera que al adelantar algo se les dé seguridad, ya que la rutina diaria da seguridad. (EP4).

Esta seguridad es importante ya que, aunque hay quien entra rápidamente en el juego, otros se muestran muy reticentes:

Las tutoras prepararon la escena y al grupo. ¿Cómo?, creando un clima mágico, pero dándoles seguridad. Se juntaron en asamblea: contaron cuentos, cantaron canciones, preguntaron ¿qué haremos hoy? Presentaron al fotógrafo que trajo un regalo, preguntó: ¿os apetece jugar? Y sacó una caja de la que apareció una gran flor blanca de papel. La vamos a tocar, la profesora se la acerca a los niños y niñas, algunos no entran en el primer momento, observan, la olemos, la tocamos, algunos se echan para atrás, ya entrarán. (EEA).

Abad también menciona la importancia de una sesión previa al juego en la que se proporcionen pautas de comportamiento:

Antes de dejarles entrar en el espacio se dan pautas de seguridad para el juego. Al comienzo hay demasiada pulsión y hace falta una anticipación, una preparación del proyecto de juego psíquicamente: no se pueden destruir las construcciones de otros niños; no se puede agredir... (CA).

El segundo tiempo se sitúa durante la acción, el profesorado que acompaña a los niños ayuda a quienes se muestran más reticentes nombrando aquello que hacen:

El profesor no participa en el juego. Los profesores son escenógrafos y le tienen que poner palabras a la narración: creación, exploración, disfrute, experimentación, imitación, complicidad, comunicación, ficción, cooperación... (CA).

La figura del profesorado es fundamental aunque no participe en el juego, porque durante el proceso el alumnado buscará su reconocimiento en algún momento, lo que les afirmará en su quehacer:

Necesitan una mirada, para apreciar que han hecho, para confirmar aquello que piensan sobre... ¡Mira lo que sabemos hacer! El educador debe estar allí, a su lado, siguiendo el juego, aceptándolo con la mirada. (CA).

El tercer tiempo se sitúa después de terminar la acción: cuando se analiza lo sucedido gracias a la documentación recogida:

Las caras de niños y niñas dicen si les hemos llegado o no. La documentación gráfica es importante, ahí se ve que la propuesta está llegando. Las fotos de niñas y niños transmiten la atención, el placer, el asombro, la forma de manifestar sus sentimientos, sus emociones. (EEA). 


\subsection{Tras la experiencia}

La experiencia con las instalaciones ha supuesto un cambio metodológico en las aulas y también en el sentir y hacer del profesorado, ayudando a construir una sólida identidad, alejada de las imágenes estereotipadas y de estéticas infantilistas:

La estética que había antes en la escuela era la considerada adecuada para infantil: colores muy fuertes, patitos y mariquitas en el papel pintado, etc. Se tiene un concepto estereotipado de la infancia (y de lo que les gusta), por ejemplo, los colores fuertes se tienen por sinónimo de alegría, ¿color es alegría?, pero hay que pensar qué van a ver continuamente. Para plantear los espacios hay que saber de niños y no sólo de arte. (EP2).

Las profesoras han aprendido que una estética cuidada, que no sature el espacio, es más efectiva a la hora de mostrar los trabajos del alumnado que una muestra abigarrada:

Nosotras al principio queríamos mostrar y mostrar...y se perdía la información. Ahora hemos aprendido a dar tiempos: poner unas cosas y quitar otras. (EP1).

De esta manera se evita la sobre-estimulación y se consigue que los niños disfruten y se sorprendan con cada nueva propuesta:

Los estímulos estéticos excesivos no son buenos, al final no se ve nada. (...) las paredes se tienen que dejar blancas una temporada, para que después todo lo que se ponga en esas paredes tenga impacto en niños y niñas, tienen que desaparecer los estímulos para aparecer de nuevo reinventados. (NC2).

Esta nueva sensibilidad estética desarrollada en la escuela pretende ser una vía de comunicación con las familias que conlleve una concienciación y una colaboración:

Queremos decorar la escuela, pero creando elementos nuevos en espacios comunes, así, mediante imágenes atractivas se establecen nuevas vías de comunicación. (EP4).

Valoramos más las sensaciones al tocar un móvil hecho con pinzas o soplar, que todos los juguetes comerciales. Poco a poco queremos conseguir que las familias se den cuenta de esto y cambien los usos de productos comerciales. (NC1).

Y que ayude a entender lo que se hace en la escuela, lo que hacen sus hijos, y aumentar su implicación en ese proyecto común que es su escuela:

Las exposiciones de cara a las familias son importantes, ya que muchas veces no entienden lo que se hace en la escuela. A través de estas acciones sí lo hacen. (EP4).

Ahora tenemos estrellas de Navidad hechas en casa por los niños con ayuda de sus familias, y sus fotografías en el proceso. A las familias les gusta mucho y las pocas que al principio no han colaborado al ver el resultado dicen: "en los próximos días traemos la nuestra". (EP3).

\section{Discusión y conclusiones}

El estudio evidencia que las instalaciones artístico-educativas pueden ser una herramienta metodológica alternativa para trabajar muchos aspectos relacionados con el desarrollo y la evolución de los niños desde una nueva perspectiva, tal y como apuntan las educadoras que participaron en esta experiencia. 
Estos ambientes plantean situaciones en las que no existe lo correcto o lo incorrecto, ni una única vía de actuación sino varias; es una invitación a la exploración de diferentes posibilidades donde es posible hacer y deshacer de manera libre, ya que no prima el resultado final sino el proceso que se realiza durante la experimentación y el desarrollo personal (Álvarez, 2014).

Según lo expresado por las docentes, la exploración y transformación de las instalaciones ofrece innumerables ambientes y situaciones de aprendizaje, pues permiten crear, imaginar o emocionarse (Cardemil y Román, 2014) a través de nuevos referentes visuales que desarrollan la sensibilidad (Duncum, 2001).

En los casos estudiados, promover nuevas transformaciones simbólicas a través de su propio cuerpo con los objetos y los espacios ha favorecido procesos cognitivos en los que imaginar nuevas soluciones a las situaciones, en los que probar, intentar o cambiar mejorando el desarrollo afectivo y emocional y trabajando la identidad a través de la imaginación, la magia y la sorpresa; promocionando las relaciones entre iguales, la re-elaboración de significados y las actitudes sensibles a partir del juego simbólico y sensoriomotriz (Abad, 2008).

Las instalaciones reflejan la idea expuesta por Malaguzzi y recogida por Hoyuelos (2010, p. 98) de que el pensamiento "se construye a partir de la acción". Es un aprendizaje constructivo (Aguirre, 2015) y social (Abad, 2012), con el alumnado como principal protagonista. Con estas experiencias, las relaciones que los niños establecieron con los elementos del espacio y las vivencias que se les proporcionaron, en palabras de los docentes, ayudó en el proceso de crecimiento y en la construcción del conocimiento acerca del mundo en el que viven, al propiciar nuevas oportunidades de interacción e interpretación (Díaz-Obregón, 2003).

El uso de las instalaciones en las escuelas supone un proceso de trabajo innovador y con poco recorrido, lo que implica que el profesorado no esté formado en esta metodología. La formación es importante, ya que los docentes deben asumir un papel múltiple sumando, al habitual de acompañamiento y guía para su alumnado, el de escenógrafos, documentalistas y mediadores con las personas, los nuevos espacios y materiales.

Los educadores, en su papel de escenógrafos, deben ofrecer planteamientos equilibrados, lugares placenteros estéticamente hablando pero también adecuados para el desarrollo motor, cognitivo y socioafectivo del alumnado; capaces de sorprender a niños y docentes. Deben buscar transformar el espacio cotidiano en un lugar estimulante e impactante, que ofrezca oportunidades abiertas a todo el alumnado a través de materiales habituales, pero cuya selección y planteamiento posibiliten su utilización y disfrute de manera distinta a la acostumbrada, ampliando las posibilidades expresivas y los referentes visuales. Elementos que, presentados de manera ordenada, induzcan a la acción de deconstruir y volver a construir. Como acompañantes, deben mostrar los materiales propiciando la curiosidad, anticipando la acción hablando de ella y, durante el proceso, aportar seguridad y ayudar a verbalizar la acción. Asimismo, se deberá analizar lo acontecido para evaluar lo ya realizado y mejorar futuras propuestas, ya que no siempre lo que se había previsto se cumple en la realidad, tal y como ocurrió con la instalación del círculo de arcilla.

El diseño previo de una instalación, la selección de los objetos y su disposición, la estética del conjunto, ayudará al éxito de la misma pero no lo garantiza, por lo que habrá que reconducirla durante la acción o de manera posterior si se detecta esa necesidad. El conocimiento sobre las necesidades y la personalidad del alumnado es básico a la hora de plantear las experiencias y sentar los criterios de próximas intervenciones.

El aprendizaje basado en la acción implica al alumnado y al profesorado. En este caso, la colaboración entre profesionales del arte y docentes ha sido una vía de aprendizaje de doble sentido. El trabajo cooperativo en el equipo docente ha resultado arduo, pero la recompensa, según los testimonios recogidos, ha valido la pena ya que la experiencia ha enriquecido al alumnado y al profesorado traspasando las fronteras del aula y transfigurando la escuela al mejorar las relaciones entre el profesorado, y con las familias a través del cambio estético de los espacios educativos, tal y como proponen la mayoría de los textos consultados (Abad, 2008; Abad y Ruiz de Velasco, 2014; Hoyuelos et al., 2015).

Entre las limitaciones del estudio cabe mencionar que ha estado enfocado principalmente en las percepciones de las personas adultas sobre la acción educativa propuesta, por lo que se podría completar con una observación más exhaustiva de la acción propiamente dicha. La edad del alumnado participante limita la recogida de sus testimonios, sin embargo, como se ha expresado, la experiencia fue documentada 
con fotografías y videos que habría que describir y analizar en un estudio posterior. Asimismo, cabría realizar experiencias similares en otras escuelas y entornos educativos que sean, al mismo tiempo, un medio para la formación del profesorado a través del aprendizaje basado en la acción.

Disponer de un sistema educativo que proporcione una enseñanza de calidad constituye una aspiración universal. Nadie mínimamente juicioso afirmaría que no desea una educación de calidad para sus hijos, comunidad o país. En 1988, la Sociedad Española de Pedagogía manifestaba que "la calidad y la excelencia son metas deseables de la educación [...] resulta difícil imaginar una escuela o una organización satisfechas en su mediocridad". (SEP, 1988, p. 7).

\section{Referencias}

Abad, J. (2008). El placer y el displacer en el juego espontáneo infantil. Papeles de Arteterapia y Educación Artística para la Inclusión Social, 3, 167-188.

https://revistas.ucm.es/index.php/ARTE/article/view/ARTE0808110167A

Abad, J. (2011). Experiencia estética y arte de participación: juego, símbolo y celebración. https://www.oei.es/historico/artistica/articulos01.htm

Abad, J. (2012). Propuestas de arte comunitario en contextos escolares. En E. Carpio (Coord.). Formas de expresión y creaciones propias. La competencia cultural y artística (pp. 5-12). Ministerio de Educación de España.

Abad, J. y Ruiz de Velasco, A. (2014). El juego simbólico. Graó.

Aguirre, I. (2015). Hacia una narrativa de la emancipación y la subjetivación desde una educación del arte basada en la experiencia. Docencia, 57, 4-15.

Álvarez, D. (2014). De la copia de láminas al ciberespacio. En R. Marín (Coord.), Didáctica de la educación artística para primaria (pp.184-227). Pearson.

Andueza, M., Barbero, A. M., Caeiro, M., Da Silva, A., García, J., González, A., Muñiz, A. y Torres, A. (2016). Didáctica de las artes plásticas y visuales en educación infantil. Universidad Internacional de La Rioja.

Aucouturier, B. (2004). Los fantasmas de acción y la práctica psicomotriz. Graó.

Bishop, C. (2008). El arte de la instalación y su herencia. Ramona. Revista de Artes Visuales Argentina, 78, 4652. https://issuu.com/nirbhe/docs/bishop la instalaci $n$ y su herencia

Callejón, M. D. y Yanes, V. (2012). Creación de entornos de aprendizaje en infantil: experiencia estética y juego. Escuela Abierta, 15, 145-161. https://ea.ceuandalucia.es/index.php/EA/issue/view/EA15

Cardemil, C. y Román, M. (2014). La importancia de analizar la calidad de la educación en los niveles inicial y preescolar. Revista Iberoamericana de Evaluación Educativa, 7 (1), 9-11.

https://revistas.uam.es/index.php/riee/article/view/3382

Dewey, J. (2010). Experiencia y educación. Biblioteca Nueva.

Díaz-Obregón, R. (2003). Arte contemporáneo y educación artística: los valores potencialmente educativos de la instalación (Tesis doctoral). Universidad Complutense de Madrid.

Díaz-Obregón, R. (2012). Artes espacio-temporales como recurso comunicativo en la educación: los descansos del mupAl. En S. Nuere y M. C. (Coords.), Arte, juego y creatividad (pp. 101-116). Eneida.

Duncum, P. (2001). Visual cultura: developments, definitions and directions for art education. Studies in Art Education, 42 (2), 101-112.

Harf, R. (2008). Si éste no es el juego: ¿el juego dónde está? Preguntas y no respuestas. En R. Harf, P. Sarlé, A. M. Porstein, M. C. Rimoli, V. Rogozinski y J. L. Leone, El Juego en la educación infantil: crecer jugando y aprendiendo (pp. 6-18). Ediciones Novedades Educativas. 
Hoyuelos, A. (2008). El taller. La pedagogía de la expresión: Loris Magaluzzi, Reggio Emilia y Pamplona. En R. Harf et al. (Coords.). Dirección y organización de instituciones para niños pequeños (pp. 87-107). Editorial CEP.

Hoyuelos, A. (2010). El taller de expresión y Loris Malaguzzi. Reflexiones sobre la relación entre niños, arte y artista. https://www.vitoria-gasteiz.org/http/wb021/contenidosEstaticos/adjuntos/es/25/33/42533.pdf

Hoyuelos, A. (2010). El taller. La pedagogía de la expresión: Loris Magaluzzi, Reggio Emilia y Pamplona. En R. Harf et al. (Coords.), Dirección y organización de instituciones para niños pequeños (pp. 87-95). Editorial CEP.

Hoyuelos, A., Cabanellas, I. y Eslava, C. (2015). Territorios de la infancia: diálogos entre arquitectura y pedagogía. Graó.

Larrañaga, J. (2016). Instalaciones. Nerea.

Malaguzzi, L. (2014). La educación infantil en Reggio Emilia. Octaedro.

Marín, R. (2014). Didáctica de la educación artística para primaria. Alhambra.

Panadés, I. y Balada, M. (2007). Situación y perspectiva de la educación artística. En M. J. Agra (Coord.), La educación artística en la escuela (pp. 11-17). Graó.

Ruiz, S. y Rebollo, M. S. (2015). El aula de educación infantil: el aula creativa. Ensayos, Revista de la Facultad de Educación de Albacete, 30(2). https://revista.uclm.es/index.php/ensayos/article/view/647/790

Sánchez, M. (2008). La instalación en España 1970-2000. Alianza Forma.

Traveset, M., Parellada, E. y León, U. (2017). R-Evolución del sistema educativo: la pedagogía sistémica multidimensional, un paradigma educativo emergente. Octaedro. 